Article

\title{
Low-Temperature Rheology and Thermoanalytical Investigation of Lubricating Greases: Influence of Thickener Type and Concentration on Melting, Crystallization and Glass Transition
}

\author{
Andreas Conrad 1,*(D), Annika Hodapp ${ }^{2}$, Bernhard Hochstein ${ }^{2}$, Norbert Willenbacher ${ }^{2}$ and Karl-Heinz Jacob $^{1}$ \\ 1 Applied Chemistry, Nuremberg Institute of Technology Georg Simon Ohm, 90489 Nuremberg, Germany; \\ karl-heinz.jacob@th-nuernberg.de \\ 2 Institute of Mechanical Process Engineering and Mechanics, Karlsruhe Institute of Technology, \\ 76131 Karlsruhe, Germany; annika.hodapp@kit.edu (A.H.); bernhard.hochstein@kit.edu (B.H.); \\ norbert.willenbacher@kit.edu (N.W.) \\ * Correspondence: andreas.conrad@th-nuernberg.de
}

check for updates

Citation: Conrad, A.; Hodapp, A.; Hochstein, B.; Willenbacher, N.; Jacob, K.-H. Low-Temperature Rheology and Thermoanalytical Investigation of Lubricating Greases: Influence of Thickener Type and Concentration on Melting, Crystallization and Glass Transition. Lubricants 2022, 10, 1. https://doi.org/10.3390/ lubricants10010001

Received: 15 November 2021 Accepted: 18 December 2021 Published: 22 December 2021

Publisher's Note: MDPI stays neutral with regard to jurisdictional claims in published maps and institutional affiliations.

Copyright: (C) 2021 by the authors. Licensee MDPI, Basel, Switzerland. This article is an open access article distributed under the terms and conditions of the Creative Commons Attribution (CC BY) license (https:/ / creativecommons.org/licenses/by/ $4.0 /)$.

\begin{abstract}
This study investigates crystallization, melting and glass transition of Li- and Ca-12hydroxystearate greases in relation to the pour point of the corresponding oils. The base oils for the greases are mineral oil, polyalphaolefin, alkylated naphthalene, propylene glycol, and trimellitate. For the mineral oil-based greases the crystallization temperature $T_{\mathrm{c}}$ increases and the melting temperature $T_{\mathrm{m}}$ decreases upon addition of thickener. The pour point of the mineral oil then is $3 \mathrm{~K}$ below $T_{\mathrm{C}}$ and does not properly define the lowest application temperature for mineral oil (MO) based greases. Both thickeners induce a small increase of the glass transition temperature (1-3 K) of the synthetic oils polyalphaolefin, alkylated naphthalene, propylene glycol. The pour point of the base oils correlates well with the onset of the glass transition in the corresponding grease indicated by a sharp increase in grease viscosity. Pure trimellitate with unbranched alkyl chains does not crystallize upon cooling but shows noticeable supercooling and cold crystallization. As the percentage of thickener in corresponding greases increases, more oil crystallizes upon cooling $20 \mathrm{~K}$ above the crystallization temperature of the trimellitate without thickener $\left(-44^{\circ} \mathrm{C}\right)$. Here, the thickener changes the crystallization behavior from homogeneous to heterogeneous and thus acts as a crystallization nucleus. The pour point of the base oil does not provide information on the temperature below which the greases stiffen significantly due to crystallization.
\end{abstract}

Keywords: lubricating grease; heterogeneous crystallization; glass transition; rheology; differential scanning calorimetry (DSC)

\section{Introduction}

Concerning the lubrication conditions in operation, the higher viscosity of the base oils and higher consistency of the greases at low temperatures, the friction factor increases slightly [1]. In the case of mineral oils, as the proportion of paraffin crystals increases with decreasing temperature, the sliding friction also increases. Nonetheless, the outflow of mineral oil provides adequate lubrication during sliding [2]. Unlike mineral oil, ester oils crystallize to the extent of blocking the rheometer [3]. Thus, it would also block a tribological contact during operation. Practical test methods such as the low-temperature torque test for wheel bearings (ASTM D4693 [4]) or ball bearings (ASTM D1478 [5]) determine the suitability of greases for low temperatures. Although these standards are close to practical experience, they do not provide information on whether the base oil in lubricating greases precipitate crystals and thus change their flow properties upon cooling. In practice, the pour point according to ASTM D97 [6] is measured for this purpose. The pour point indicates the temperature when the base oil stops flowing as a sample vessel is tilted. Previous research 
has shown that crystallization and viscosity increase are responsible for oils stop flowing at temperatures below the pour point. However, some oils can crystallize at temperatures above the pour point if given enough time [3].

Mineral oils precipitate paraffin crystals below the crystallization temperature $\left(T_{\mathrm{c}}\right)$, turning Newtonian mineral oils into shear-thinning suspensions. The transition from Newtonian to viscoelastic behavior is indicated by a significant slope increase in an Arrhenius diagram $\left(\ln (\eta)-T^{-1}\right)$ below the crystallization temperature [7]. The necessary supercooling $\left(\Delta T=T_{\mathrm{c}}-T_{\mathrm{m}}\right)$ for precipitation of paraffin crystals is hardly dependent on the shear rate and the cooling conditions and is almost constant at about $\Delta T=-10 \mathrm{~K}$. The crystallization temperature can be equated with the pour point of mineral oils [3].

Unlike mineral oils, which are mixtures of paraffinic, naphthenic, and aromatic hydrocarbons, synthetic oils consist of chemically uniform compounds with a comparatively narrow molecular weight distribution. The synthetic oils polyalphaolefin, polyalkylenglycole, alkylated naphthalene, and tris-(2-ethylhexyl)trimelltiate solidify glass-like below $-70{ }^{\circ} \mathrm{C}$. Upon cooling, the viscosity of these base oils increases steadily and follows a WilliamsLandes-Ferry Equation (WLF) down to $20 \mathrm{~K}$ above the glass transition temperature [3].

Ester oils with linear alkyl chains and a narrow molecular weight distribution crystallize with strong supercooling effects [8]. Using the example of a trimellitate with linear alkyl chains (C8-C10), the viscosity increases steadily up to the crystallization temperature. At the crystallization temperature, the viscosity rises abruptly. However, crystallization does not lead to shear-thinning suspensions as in mineral oils but to a solid [3].

The crystallization temperatures of a base oil in a lubricating grease may differ from the pure base oil due to the catalytic effect the thickener on crystallization, i.e., heterogeneous crystallization. From a thermodynamic point of view, nucleation in a base oil is spontaneous when the size of nuclei corresponds to a critical size, which decreases with increasing supercooling $\left(\Delta T=T_{\mathrm{c}}-T_{\mathrm{m}}\right)$. Particles in a liquid can act as nuclei with a larger critical nucleation radius, resulting in a lower energy barrier for nucleation and less supercooling [9]. The necessary condition for particles to catalyze nucleation is that they have melting temperatures far higher than the melting point of the lubricating oil and remain solid, which is the case for common thickeners such as Li- and Ca-12-hydroxystearate [10].

From a kinetic point of view, the rate of nucleus formation depends on viscosity, i.e., the lower the temperature, the lower the nucleation rate. Approaching the glass-transition temperature $T_{\mathrm{G}}$, the nucleation rate becomes infinitely small. Since the temperatures for a maximum nucleation rate and maximum crystal growth rate are not identical, lubricating oil composition and cooling rate significantly influence supercooling. When the maximum crystal growth rate temperature is below the glass temperature $T_{\mathrm{G}}$, nuclei are absent, and glass-like solidification takes place upon cooling [10,11].

If such base oils are processed into lubricating greases with $\mathrm{Li}$ - or Ca-12-hydroxy stearate, the thickener type and concentration determine the consistency of the metal soap greases. The metal soap must be melted in the base oil and then cooled under defined conditions. During this process, a thickener structure forms, which is responsible for the viscoelasticity of the lubricating greases [12]. With Li-12-hydroystearate as a thickener, a network of platelets is formed at low concentrations, which changes into fine and dense fibril-like structures at higher concentrations [13]. Calcium complex soaps, for example, build globular structures [14]. Even at relatively low thickener concentrations, metallic soaps cause viscoelasticity of the lubricating greases and, above a specific concentration, forming a viscoelastic liquid with a yield point [15].

In the context of base oils and associated lubricating greases, the question arises whether and what influence the thickener type, and concentration have on crystallization, melting, and glass transition temperatures. These questions are discussed in detail below, based on rheological and thermoanalytical measurements for various lubricating greases. The relevance of the base oils' pour point for the low-temperature behavior of corresponding greases will also be addressed. 


\section{Materials and Methods}

Table 1 lists the base oils used with the kinematic viscosities at 40 and $100{ }^{\circ} \mathrm{C}$, the viscosity index, and the respective pour point. The crystallization behavior and lowtemperature rheology is previously examined in detail and the base oils are classified in three groups [3]. Group I contains a mineral oil (MO), Group II includes amorphously solidifying synthetic lubricating oils (PAG, KR-008, PAO8), and Group III comprises a crystallizing synthetic lubricating oil (EO).

Table 1. Classification (Group I-III), kinematic viscosity (v), viscosity index (VI), pour point (ASTM D7346 [16]), and chemical nature of the base oils.

\begin{tabular}{ccccccc}
\hline & Chemical Nature & Group & $\boldsymbol{v} @ \mathbf{4 0}{ }^{\circ} \mathbf{C} / \mathbf{c S t}$. & $\boldsymbol{v} @ \mathbf{1 0 0}{ }^{\circ} \mathbf{C} / \mathbf{c S t}$. & VI & Pour Point $/{ }^{\circ} \mathbf{C}$ \\
\hline MO & mineral oil (SN 100/SN 500) & I & 48 & 5.3 & 105 & -12 \\
PAO8 & polyalphaolefin & II & 47 & 8 & 139 & -66 \\
KR-008 & alkylated naphthalene & II & 36 & 7 & 68 & -54 \\
PAG & polypropylenglycole & II & 57 & 10.4 & 188 & -51 \\
EO & Trimellititate * & III & 52 & 8.1 & 128 & -57 \\
\hline
\end{tabular}

* with linear C8-C10 alkyl groups.

From the base oils listed in Table 1, lubricating greases with Li- and Ca-12-hydroxystearate were prepared. Ca-12-hydroxystearate greases were prepared by melting the Ca-12hydroxystearate in the base oil at $120{ }^{\circ} \mathrm{C}$ for $30 \mathrm{~min}$, while the Li-12-hydroxystearate lubricating greases were prepared by melting Li-12-hydroxystearate above the melting point of $212{ }^{\circ} \mathrm{C}$. After cooling to room temperature, homogenization of the cooled suspensions was carried out on a three-roll mill (Exakt Advanced Technologies GmbH, 50I, Norderstedt, Germany). Greases with thickener concentrations lower than 5 wt.\% were homogenized with an Ultra-Turrax (IKA GmbH, Staufen, Germany). Table A1 in the appendix lists the exact composition of the lubricating greases with the respective worked penetration $P_{\mathrm{w}}$ (DIN ISO 2137 [17]) and corresponding NLGI class (DIN 51818 [18]).

\subsection{Rheological Measurements}

The steady shear measurements were performed with MCR301 and 702 rheometers from Anton Paar (Ostfildern-Scharnhausen, Germany). A plate-plate geometry with $25 \mathrm{~mm}$ in diameter (PP25) made of stainless steel was used as measuring system with a gap of $1 \mathrm{~mm}$. In the temperature range between 20 and $-40{ }^{\circ} \mathrm{C}$ the Peltier unit was purged with dry air (dew point: $-80^{\circ} \mathrm{C}$ ) to prevent condensation and freezing of humidity. Measurements below $-40{ }^{\circ} \mathrm{C}$ were performed using a PP25 geometry covered by a low-temperature CTD450 cell and an EVU10 controller for liquid nitrogen, both from Anton Paar (OstfildernScharnhausen, Germany). Temperature-dependent oscillatory shear measurements were performed at an angular frequency of $\omega=10 \mathrm{rad} \mathrm{s}^{-1}$ and an amplitude of $\gamma=0.05 \%$. Strict care was taken to ensure that the linear viscoelastic (LVE) range was maintained in the temperature range investigated. All rheological experiments were performed in triplicate with fresh samples for each measurement.

\subsection{Differential Scanning Calorimetry (DSC)}

Heat flow measurements during the cooling and heating cycles were performed with a DSC 204 F1 Phoenix ${ }^{\circledR}$ (Netzsch, Selb, Germany) in a pierced aluminum pan with a sample weight of approx. $10 \mathrm{mg}$ to detect glass transition, crystallization, and melting of the lubricating greases. The measurements were carried out in the temperature range from 25 to $-60{ }^{\circ} \mathrm{C}$ with heating and cooling rate of $2 \mathrm{~K} \mathrm{~min}^{-1}$. For the extended temperature range down to $-180{ }^{\circ} \mathrm{C}$, a Netzsch DSC 204 cell with a CC 200 L controller for liquid nitrogen was used. The lubricating grease samples were cooled with $-20 \mathrm{~K} \mathrm{~min}^{-1}$ from $25{ }^{\circ} \mathrm{C}$ to $-180{ }^{\circ} \mathrm{C}$, held for $5 \mathrm{~min}$, and then heated with a rate of $+10 \mathrm{~K} \mathrm{~min}^{-1}$. All thermoanalytical experiments were performed in triplicate with fresh samples for each measurement. 


\section{Results and Discussion}

\subsection{Crystallization and Melting of Lubricating Greases Based on Mineral Oil (Group I)}

Figure 1 shows the absolute value of the complex viscosity $\left|\eta^{*}\right|$ as a function of the temperature for the pure mineral oil (MO) and two mineral oil greases, with different Li(a) and Ca-12-hydroxystearate (b) concentrations during cooling (empty symbols) and heating (filled symbols). Upon cooling, the complex viscosity increases steadily until the crystallization temperature $T_{\mathrm{c} \text {,rheo }}$ is reached. Below $T_{\mathrm{c} \text {,rheo, }}$ the slope of the complex viscosity curve increases sharply. The complex viscosity increases levels off below $-20{ }^{\circ} \mathrm{C}$. On reheating, the complex viscosity of the greases first decreases sharply until the melting temperature $T_{\mathrm{m} \text {,rheo }}$ is reached, which is always higher than $T_{\mathrm{c} \text {,rheo }}$. Above $T_{\mathrm{m} \text {,rheo, }}$, the absolute values of the complex viscosities of the cooling and heating cycles overlap. The reason for the sharp change in slopes on cooling and heating, respectively, is the formation and dissolution of paraffin crystals. Previous investigations on the mineral oil MO have shown that the MO changes from a Newtonian liquid to a shear-thinning suspension below $T_{\text {c,rheo }}[3]$.

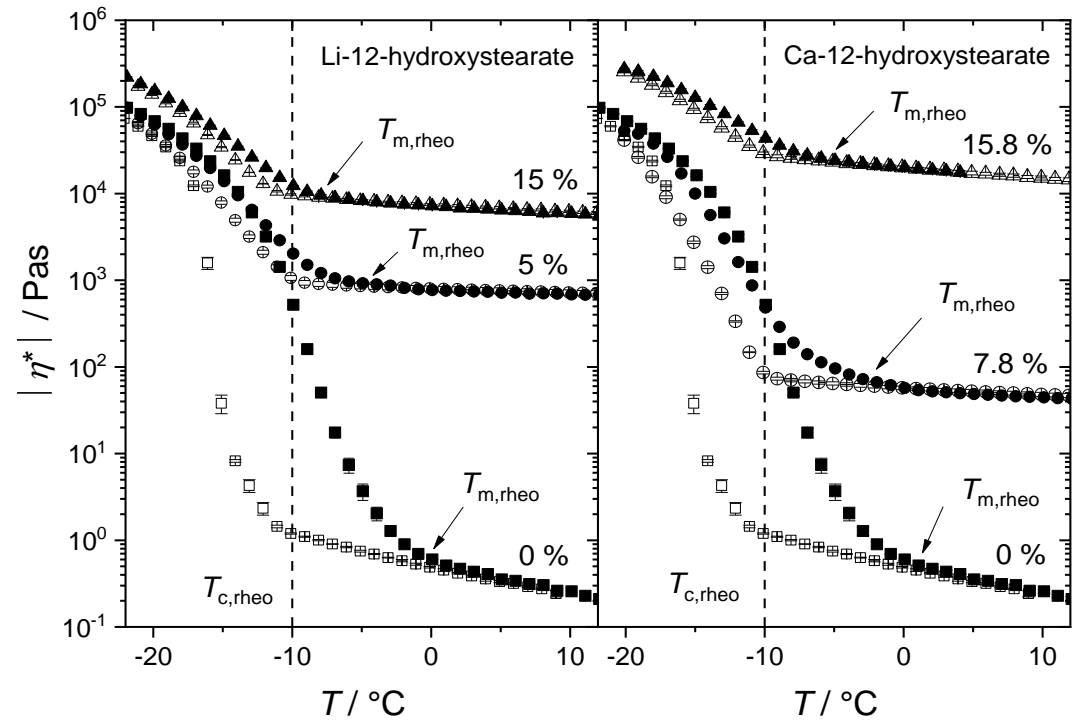

(a)

(b)

Figure 1. Absolute value of the complex viscosity $\left|\eta^{*}\right|$ as a function of temperature from cooling (empty) and heating (filled) of pure mineral oil and two lubricating greases based on mineral oil of different proportions of (a) $\mathrm{Li}$ and (b) Ca-12 hydroxystearate at a heating and cooling rate $\beta$ of $2 \mathrm{~K} \mathrm{~min}^{-1}$, angular frequency $\omega$ of $10 \mathrm{rad} \mathrm{s}^{-1}$ and deformation $\gamma$ of $0.05 \%$. The dashed line marks the crystallization temperature $T_{\mathrm{c} \text {,rheo }}$ and the melting temperatures $T_{\mathrm{m} \text {,rheo }}$ are marked by arrows.

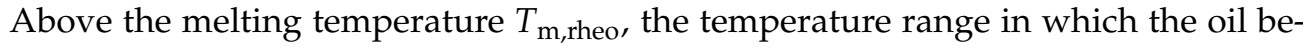
haves Newtonian, the level of the complex viscosity increases with increasing thickener concentration from 0.5 Pas without thickener to approx. $10^{4}$ Pas with $15.0 \mathrm{wt}$.\% Li-12hydroxystearate and $15.8 \mathrm{wt} \% \mathrm{Ca}-12$-hydroxystearate as thickener, respectively. Below the temperature of $-20{ }^{\circ} \mathrm{C}$, the viscosity reaches a level of about $10^{5}$ Pas regardless of thickener type and concentration. The complex viscosity of the greases at temperatures lower than $-20{ }^{\circ} \mathrm{C}$ is affected mainly by the presence of paraffin crystals.

Figure 2 depicts the crystallization temperatures $T_{c, \text { rheo }}$ and melting temperatures $T_{\text {m,rheo }}$ of mineral oil greases with Li- (a) and Ca-12-hydroxystearate (b) as a function of thickener concentration. $T_{c \text {,rheo }}$ and $T_{\mathrm{m} \text {,rheo }}$ were obtained by intersecting two tangents above and below the significant slope change in Figure 1. The mineral oil without thickener exhibits a crystallization temperature $T_{\mathrm{c} \text {,rheo }}$ of $-11.7 \pm 0.15^{\circ} \mathrm{C}$ and a melting temperature $T_{\mathrm{m} \text {,rheo }}$ of $-0.8 \pm 1^{\circ} \mathrm{C}$. Regardless of Li- or Ca-12-hydroxystearate greases, the crystallization temperatures increase to values between -8 and $-10{ }^{\circ} \mathrm{C}$, and the melting temperatures 
decrease to values between -5 and $-7{ }^{\circ} \mathrm{C}$. The supercooling $\left(\Delta T=T_{\mathrm{c}}-T_{\mathrm{m}}\right)$ decreases from approx. $11 \mathrm{~K}$ without thickener to approx. $3 \mathrm{~K}$ for Li-12-hydroxystearate and approx. $5 \mathrm{~K}$ for Ca-12-hydroxystearate greases at a thickener concentration of about $5 \mathrm{wt} . \%$ and essentially remains constant when the fraction of thickener is further increased.

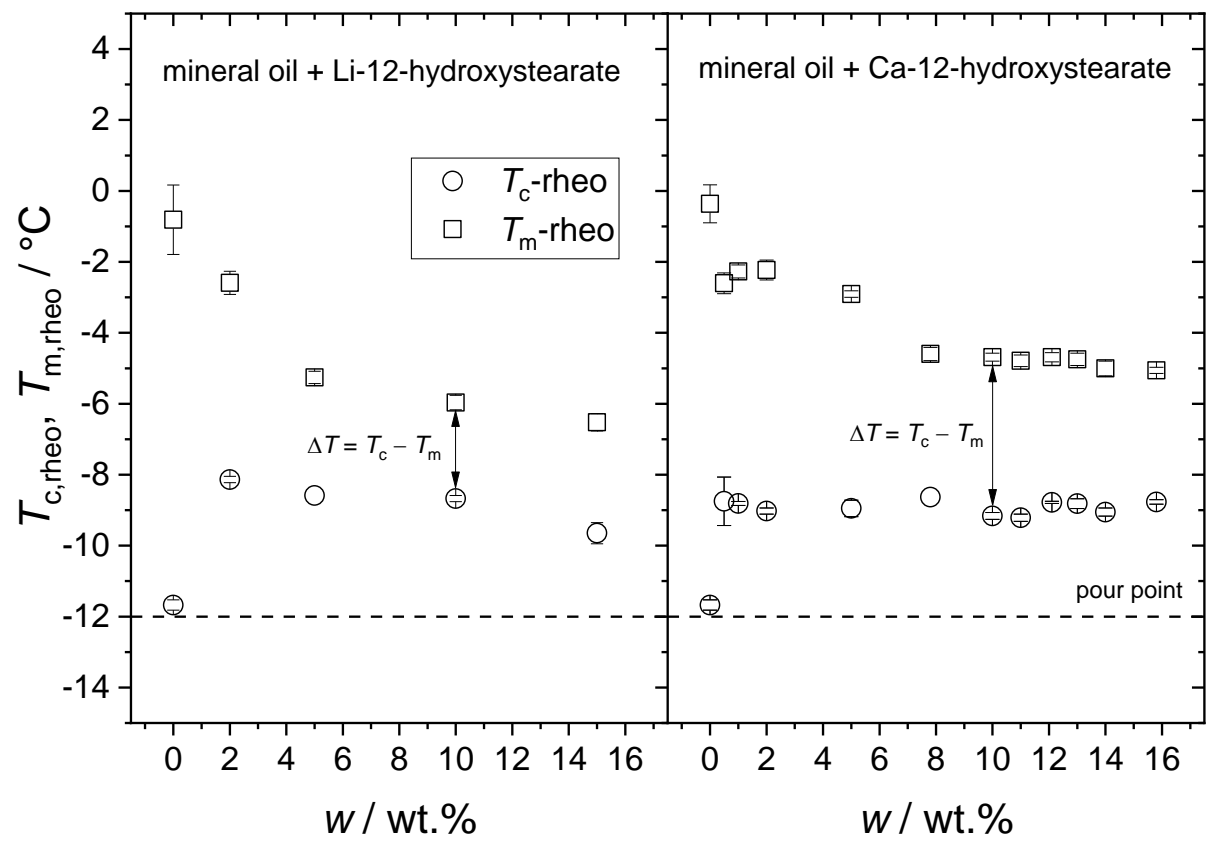

(a)

(b)

Figure 2. Crystallization- $\left(T_{\mathrm{c}, \text { rheo }}\right)$ and melting temperature $\left(T_{\mathrm{m}, \mathrm{rheo}}\right)$ as a function of thickener concentration $w$ for Li-12-hydroxystearate (a) and Ca-12-hydroxystearate (b) based on mineral oil (MO), obtained from small amplitude oscillatory shear rheometry cooling and heating cycles (see Figure 1) with an angular frequency $\omega=10 \mathrm{rad} \mathrm{s}^{-1}$, deformation $\gamma=0.05 \%$ cooling and heating rate of $\beta=2 \mathrm{~K} \mathrm{~min}^{-1}$. $T_{\mathrm{c} \text {,rheo, }}$ and $T_{\mathrm{m} \text {,rheo }}$ are obtained by intercepting two tangents above and below the significant slope change in Figure 1. The supercooling $\left(\Delta T=T_{\mathrm{C}}-T_{\mathrm{m}}\right)$ decreases from approx. $11 \mathrm{~K}$ without thickener to approx. $3 \mathrm{~K}$ with Li-12-hydroxystearate and approx. $5 \mathrm{~K}$ with Ca-12-hydroxystearate. A dashed line marks the pour point of $-12{ }^{\circ} \mathrm{C}$.

The increase in crystallization temperature $T_{c, \text { rheo }}$ is presumably caused by the thickener particles in the base oil. The thickener particles provide crystal nuclei, favoring the formation of paraffin crystals at higher temperatures, here about $-8{ }^{\circ} \mathrm{C}[9,10]$. Consequently, the crystallization temperature of the lubricating greases is $4 \mathrm{~K}$ above the pour point of the mineral oil $\left(-12^{\circ} \mathrm{C}\right)$. A small amount of dissolved thickener in the base oil presumably causes the decrease in $T_{\mathrm{m}}[19]$.

\subsection{Lubricating Greases Based on Non-Crystallizing Synthetic Base Oils (Group II)}

Figure $3 a$ displays the absolute value of the complex viscosity and Figure $3 b$ the specific heat flow $\dot{q}$ as a function of temperature for the grease with the synthetic base oil PAO8 and 22 wt.\% Li-12-hydroxystearate (PAO8-22) as a thickener. In the logarithmic plot, the complex viscosity increases approximately linearly with decreasing temperature up to the onset of the glass transition $\left(T_{\mathrm{G}, \mathrm{PAO} 8-22}=-83 \pm 0.2{ }^{\circ} \mathrm{C}\right)$. The absolute value of the complex viscosity increases sharply in the temperature interval between $-66^{\circ} \mathrm{C}$ and $T_{\mathrm{G}}$, but remains constant at a high level of $10^{7}$ Pas below $T_{G}$. The lubricating greases based on KR-008 (Figure A1) and PAG (Figure A2) behave similarly, see Appendix A. Notably, the temperature at which the two tangents fitted to the sections of the $\left|\eta^{*}\right|$ curve with different slope agrees with the pour point and the end of the section in which $\left|\eta^{*}\right|$ steeply increases corresponds to the glass transition temperature. According to the nucleation theory, for 
oils such as PAO8, the maximum temperature of crystal growth rate is below the glass temperature $T_{\mathrm{G}}[10,11]$.

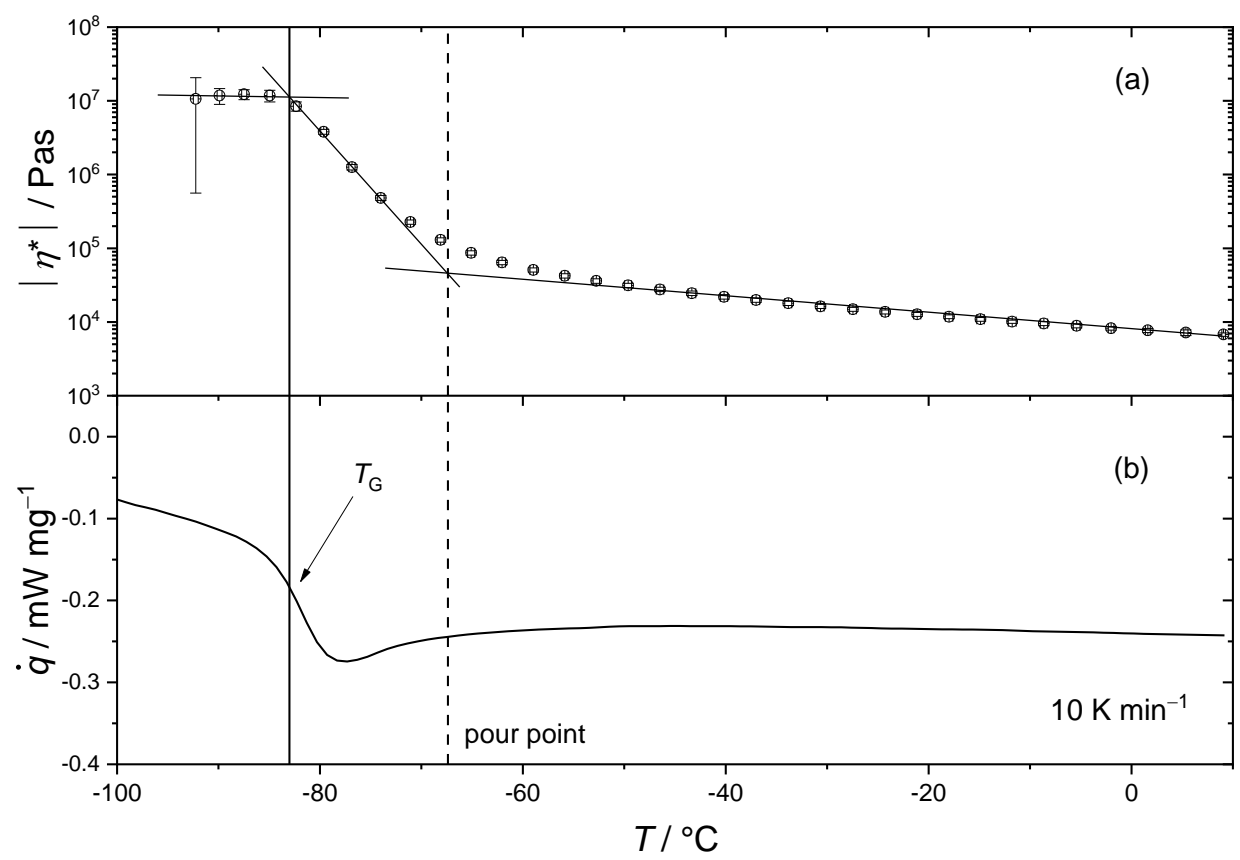

Figure 3. (a) Absolute value of complex viscosity $\left|\eta^{*}\right|$ as a function of temperature for the lubricating grease made from the base oil PAO8 with $22 \mathrm{wt}$ \% Li-12-hydroxystearate as a thickener (PAO8-22), measured in oscillatory shear with the deformation amplitude $\gamma=0.05 \%$, angular frequency $\omega=10 \mathrm{rad} \mathrm{s}^{-1}$ and cooling rate of $-10 \mathrm{~K} \mathrm{~min}^{-1}$. Lines are to guide the eye. (b) Specific heat flow $\dot{q}$ of the PAO8-22 grease at a heating rate of $10 \mathrm{~K} \mathrm{~min}^{-1}$. PAO8 shows a glass transition temperature $T_{\mathrm{G}}$ at $-83 \pm 0.2^{\circ} \mathrm{C}$, marked by a solid line. The dashed line marks the pour point for the base oil PAO8 of $-66^{\circ} \mathrm{C}$.

Figure 4 compares the glass transition temperatures $T_{\mathrm{G}}$ of the base oils PAO8, KR-008 and PAG (abscissa) and the corresponding lubricating greases (ordinate) with $\mathrm{Li}$ and $\mathrm{Ca}-12$ hydroxystearate as a thickener. Glass transition temperature of the lubricating greases is always slightly higher $(\approx 2 \mathrm{~K})$ than that of the corresponding base oil but hardly depends on the thickener concentration at least in the investigated concentration range and stays always below $-70^{\circ} \mathrm{C}$. The solidification behavior of greases based on non-crystallizing synthetic base oils does not change significantly due to the added thickener. The pour point as well as the glass transition temperature for these base oils and lubricating greases, respectively, are good indicators for their lowest application temperature.

\subsection{Greases Based on Crystallizing Synthetic Base Oils (Group III)}

The absolute value of the complex viscosity of the lubricating greases based on the trimellitate EO increases uniformly on cooling down to the crystallization temperature $T_{\mathrm{c}}$ and then rises abruptly. The ester crystallizes to such an extent that the rheometer blocks, and no further measurements are possible [3]. For this reason, the crystallization behavior of trimellitate greases was investigated primarily using differential scanning calorimetry (DSC).

Figure 5 shows the heat flux from DSC measurements during cooling (a) and reheating (b) for Ca-12 hydroxystearate lubricating greases with thickener concentrations between 0.5 and $13 \mathrm{wt} . \%$. During cooling, in the temperature range between $-10{ }^{\circ} \mathrm{C}$ and $-50{ }^{\circ} \mathrm{C}$, an exothermic signal arises at thickener concentrations higher than $1 \mathrm{wt} . \%$, which increases in magnitude with increasing thickener concentration and the peak shifts to higher temperatures. The onset temperature increases slightly. 


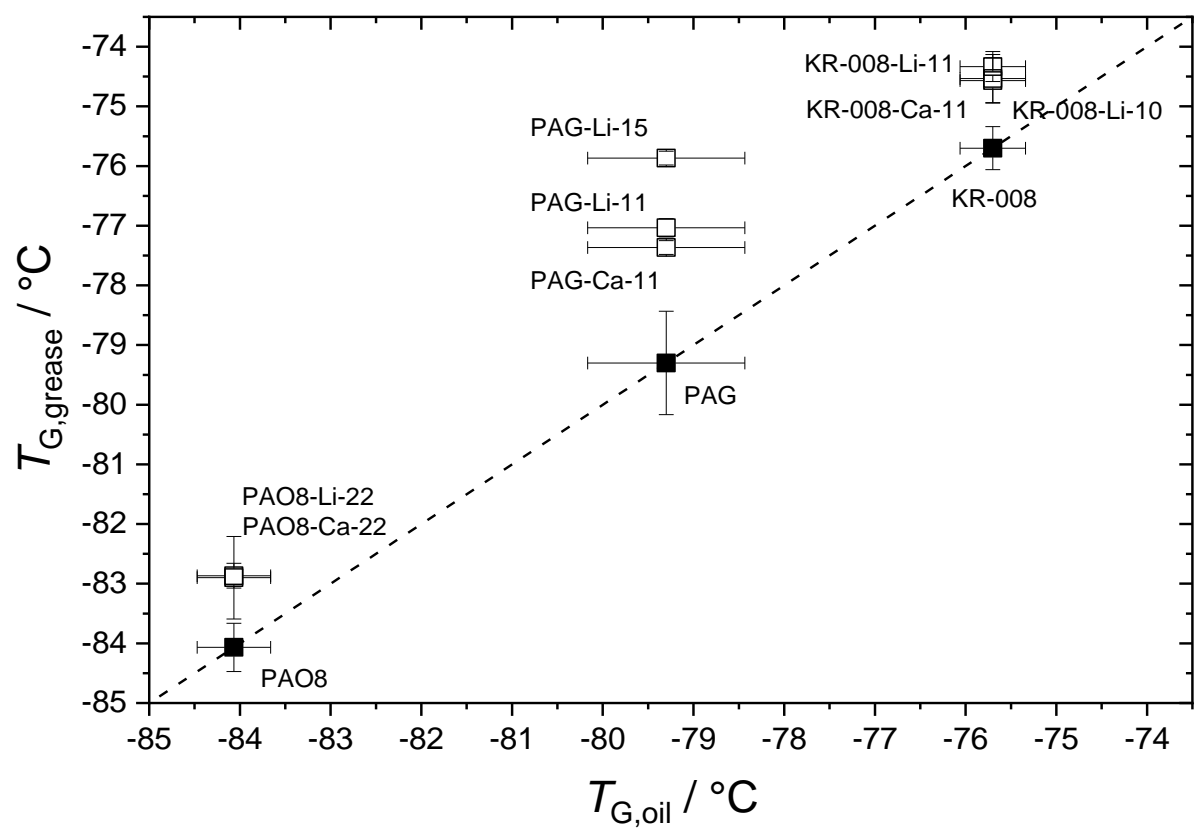

Figure 4. Comparison of the glass transition temperatures of pure base oils PAO8, KR-008, and PAG (abscissa) and lubricating greases with different Li and Ca-12-hydroxystearate concentrations (ordinate) obtained from DSC-measurements at $10 \mathrm{~K} \mathrm{~min}^{-1}$. PAO8 with 22 wt.\% (PAO8-Li-22, PAO8Ca-22), KR-008 with 10 and 11 wt.\% (KR-008-Li-10, KR-008-Li-11, KR-008-Ca-11) and PAG with 11 and $15 \mathrm{wt} . \%$ (PAG-Li-11, PAG-Li-15, PAG-Ca-11). The dashed line represents the angle bisector on which the $T_{\mathrm{G}}$ 's of the pure oils lie (PAO8, PAG, and KR-008).

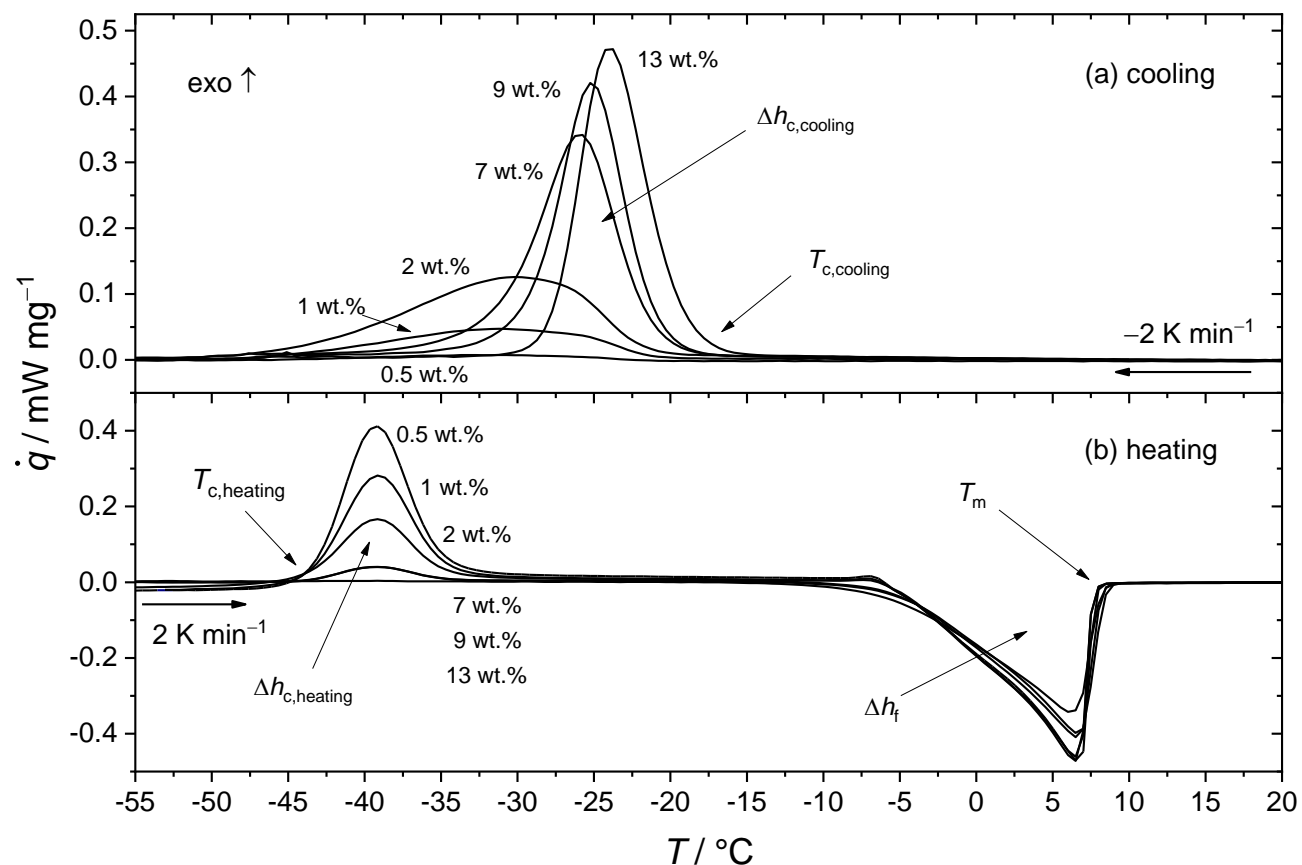

Figure 5. Heat flow $\dot{q}$ as obtained from DSC measurements during cooling (a) and reheating (b) for Ca-12 hydroxystearate greases with thickener concentrations of $0.5,1,2,7,9$, and 13 wt.\% with trimellitate (EO) as base oil at a cooling (a) and heating (b) rate of $2 \mathrm{~K} \mathrm{~min}^{-1}$. The integral of the exothermic signals during cooling and heating represent the crystallization enthalpy $\Delta h_{\mathrm{c}, \text { cooling }}$ and $\Delta h_{\mathrm{c} \text {,heating, }}$ respectively. The integral of the endothermic peak represents the enthalpy of fusion (i.e., melting) $\Delta h_{\mathrm{f}} . T_{\mathrm{c} \text {,cooling }}$ and $T_{\mathrm{c} \text {,heating }}$ are the onset temperatures of the crystallization peaks. $T_{\mathrm{m}}$ is the offset of the melting peak. 
In addition, an exothermic peak is observed during heating in the temperature range between $-45^{\circ} \mathrm{C}$ and $-30{ }^{\circ} \mathrm{C}$. The crystallization enthalpy during heating $\Delta h_{c}$,heating decreases with increasing thickener concentration and is not measurable anymore for thickener concentrations $>9 \mathrm{wt}$.\%; peak temperatures and peak widths remain the same. Above $-10{ }^{\circ} \mathrm{C}$, melting of the sample begins. Melting temperature and area of the endothermic peak do not change with thickener concentration. However, the peak becomes somewhat flatter and broader with increasing thickener concentration.

Figure 6 shows melting temperature $T_{\mathrm{m}}$ and crystallization temperature during cooling $\left(T_{\mathrm{c}, \text { cooling }}\right)$ and heating $\left(T_{\mathrm{c}, \text { heating }}\right)$ of the trimellitate $(\mathrm{EO})$ based Li- and Ca12-hydroxystearate greases as a function of thickener content. The melting temperature $T_{\mathrm{m}}=7.8 \pm 0.4{ }^{\circ} \mathrm{C}$ is independent of thickener type and concentration and the same is true for the crystallization temperature determined during the heating cycle $T_{c, \text { heating }}=-46.1 \pm 1.9^{\circ} \mathrm{C}$.

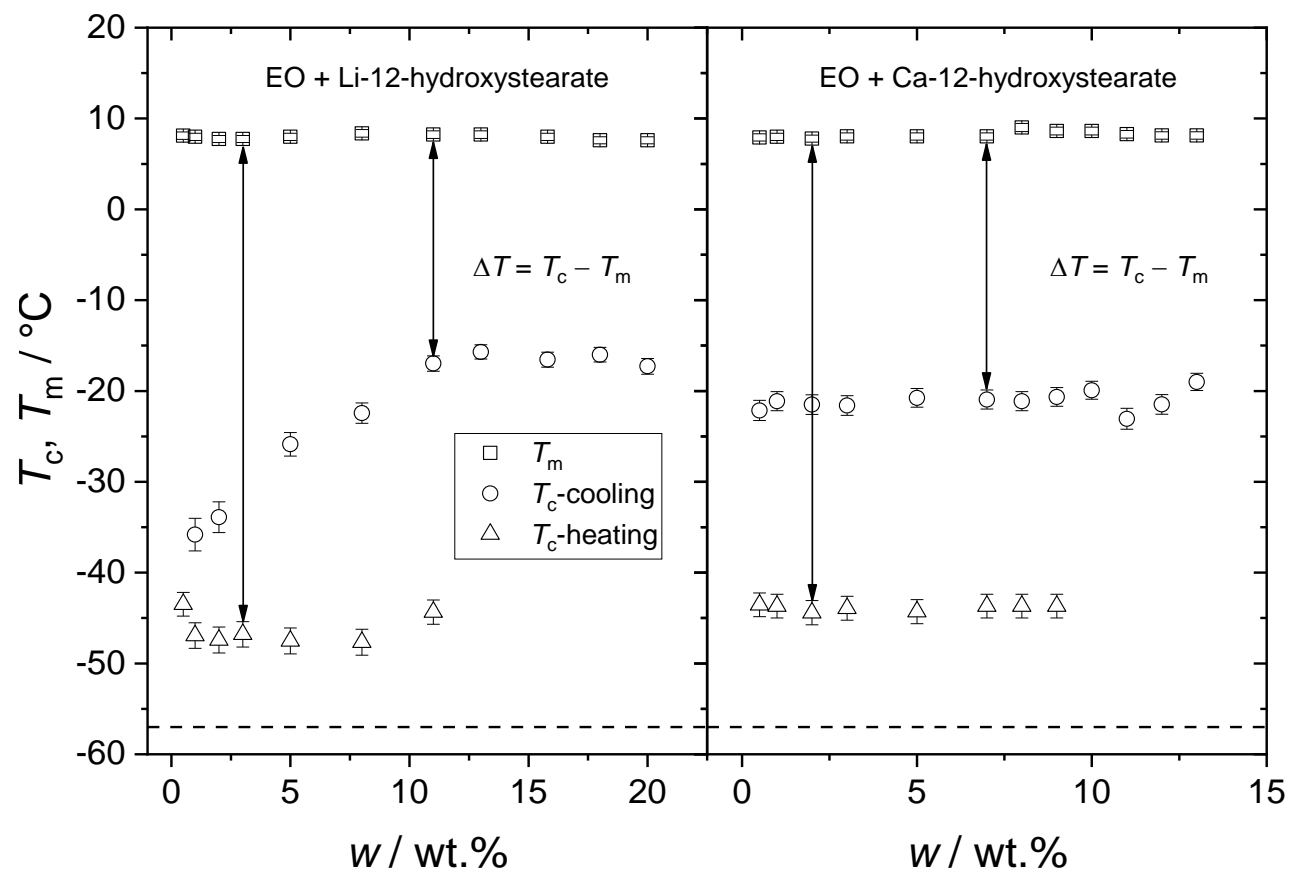

(a)

(b)

Figure 6. Crystallization temperatures obtained during cooling $\left(T_{c, \text { cooling }}\right)$ and heating cycles ( $T_{\mathrm{c}, \text { heating }}$ ) and melting temperature $T_{\mathrm{m}}$, as a function of thickener concentration $w$ for Li-12hydroxystearate (a) and Ca-12-hydroxystearate greases (b) based on trimelltiate (EO), obtained from the onset temperature of the exothermic peaks of DSC measurements with $2 \mathrm{~K} \mathrm{~min}^{-1}$ cooling and heating rate (Figure 5). The crystallization temperature at heating $T_{c, \text { heating }}$ is independent of the thickener fraction at about $-45^{\circ} \mathrm{C}$, and the melting temperature is about $7.8 \pm 0.4^{\circ} \mathrm{C}$. The dashed line marks the pour point of $-57^{\circ} \mathrm{C}$.

The pure ester (EO) does not crystallize upon cooling but only upon heating $\left(T_{\mathrm{c}, \text { heating }}=-43 \pm 0.3^{\circ} \mathrm{C}\right)$. The presence of thickener causes the oil to crystallize during both, cooling and heating cycles. For Li-12-hydroxystearate contents between 1 and $11 \mathrm{wt} . \%$ crystallization can be observed upon cooling and heating, for thickener contents above $11 \mathrm{wt} . \%$ only during cooling. Up to a thickener concentration of $11 \mathrm{wt} . \%$ the crystallization

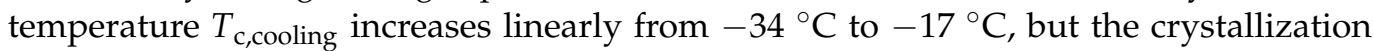

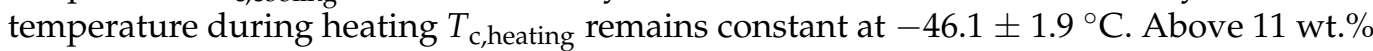
the Li-12-hydroxystearate greases crystallize only during cooling and the crystallization temperature is $T_{\mathrm{c}, \text { cooling }}=-16.7 \pm 0.7^{\circ} \mathrm{C}$. 
The trimellitate (EO) in Ca-12-hydroxystearate greases crystallizes at thickener concentrations between 0.5 and $9 \mathrm{wt} . \%$ during cooling and heating and above $9 \mathrm{wt} . \%$ only during cooling. With increasing thickener concentration, the crystallization temperature upon cooling increases slightly from $-22.1 \pm 1.1{ }^{\circ} \mathrm{C}$ to $-19.0 \pm 1.0^{\circ} \mathrm{C}$, whereas the crystallization temperature upon reheating remains constant at $-43.7 \pm 0.4{ }^{\circ} \mathrm{C}$, irrespective of thickener concentration.

The enthalpy of fusion $\Delta h_{\mathrm{f}}=92.5 \pm 3.0 \mathrm{~J} \mathrm{~g}^{-1}$ (endothermic, Figure $5 \mathrm{~b}$ ) is larger than the crystallization enthalpy $\Delta h_{\mathrm{c}}=73.5 \pm 6.0 \mathrm{~J} \mathrm{~g}^{-1}$ because crystal growth is to some extent too slow to cause a detectable heat flux signal. Furthermore, the total enthalpy of fusion $\Delta h_{\mathrm{f}}$ and crystallization $\Delta h_{\mathrm{c}}$ are independent of the thickener concentration, indicating that only the base oil crystallizes.

Figure 7 shows the specific enthalpies of crystallization of the greases based on trimellitate (EO) during cooling $\Delta h_{\mathrm{c}, \text { cooling }}$ (a) and heating $\Delta h_{\mathrm{c} \text {,heating }}$ (b) relative to the total

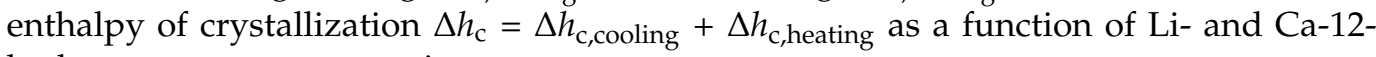
hydroxystearate concentration.

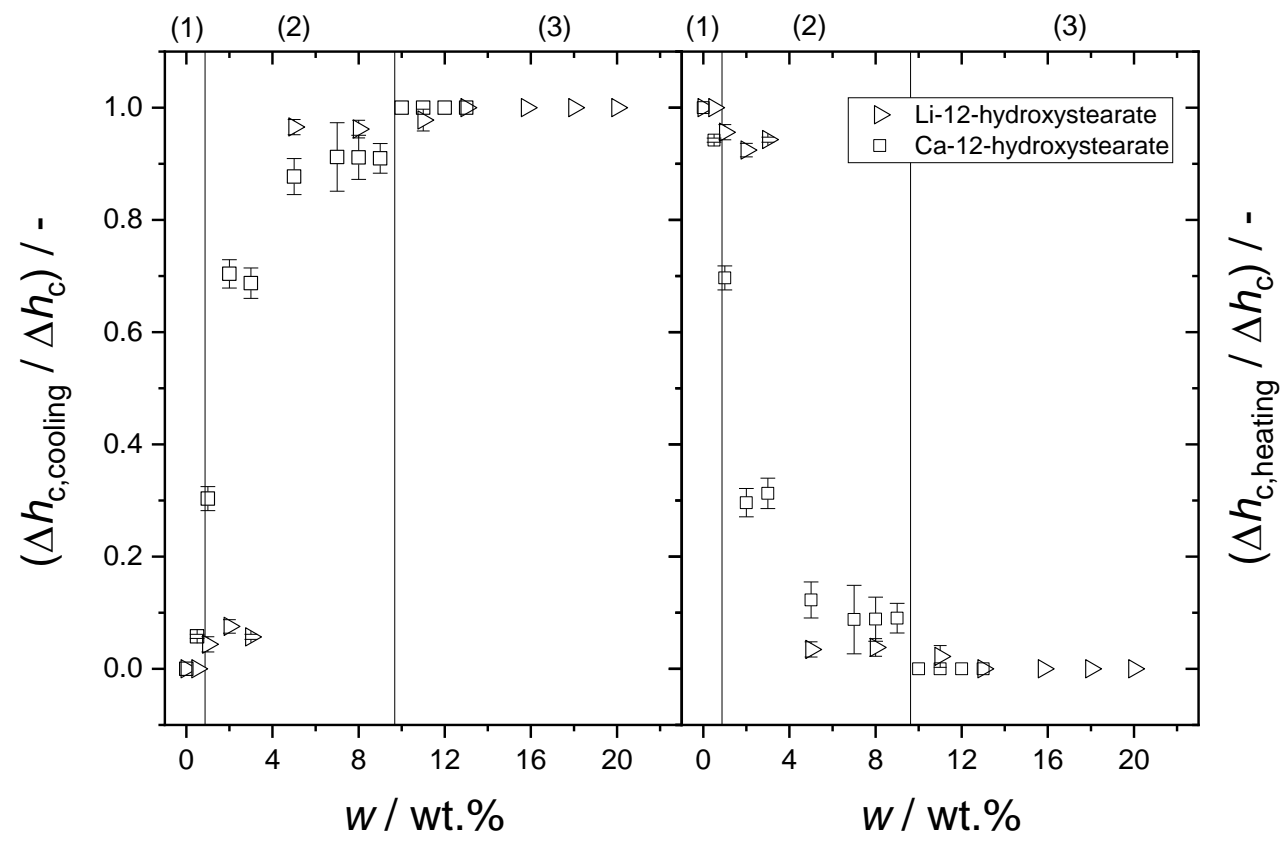

(a)

(b)

Figure 7. Specific enthalpies of crystallization during cooling $\Delta h_{\mathrm{c}, \text { cooling }}$ (a) and heating $\Delta h_{\mathrm{c} \text {,heating }}$ (b) normalized to the total enthalpy of crystallization $\Delta h_{\mathrm{c}}=\Delta h_{\mathrm{c}, \text { cooling }}+\Delta h_{\mathrm{c} \text {, heating }}$ of the trimellitate (EO) based greases vs. concentration of Li- and Ca-12-hydroxystearate as determined from DSC measurements (see Figure 5) at cooling/heating rates of $2 \mathrm{~K} \mathrm{~min}^{-1}$. The total enthalpy of crystallization remains constant at $\Delta h_{\mathrm{c}}=73.5 \pm 6.0 \mathrm{~J} \mathrm{~g}^{-1}$ for both types of thickeners. Ranges (1-3) highlight the shift in the supercooling effect. Range (1) indicates predominantly cold crystallization, (2) crystallization upon cooling and heating, and (3) predominantly crystallization upon cooling.

According to ISO 11357-7 [20] the exothermic peaks' total area during cooling and heating corresponds to complete crystallization, and thus the percentage of crystallization during cooling and heating can be calculated. Figure 7 depicts that the percentage of crystallizing base oil upon cooling increases with increasing thickener concentration. As already shown in Figure 5, this indicates a monotonically increasing proportion of heterogeneous crystallization. At thickener concentrations $>9 \mathrm{wt} . \%$ Ca-12-hydroxy stearate and $>11 \mathrm{wt} . \%$ Li-12-hydroxystearate, respectively, only crystallization during cooling occurs because heterogeneous nucleation is predominant. 
In the case of the pure trimellitate (EO), nuclei form below the temperature range in which crystal growth is optimal. In case of greases, the thickener creates interfaces at which nuclei can form in the temperature range in which crystal growth takes place. Since nuclei are present, crystal growth is detectable as an exothermic DSC signal [9-11].

At low thickener concentrations (0-9 wt.\% for Ca-12-hydroxystearate and 0-11 wt.\% Li-12-hydroxystearate) only a few nuclei are present. Therefore, only a few crystals start to grow, and the crystal growth rate is not fast enough for complete crystallization before reaching the lowest measuring temperature (see Figure 5a).

At thickener concentrations $>9$ wt.\% for Ca-12-hydroxystearat and $>11 \mathrm{wt} \%$ for Li-12-hydroxystearate, sufficient amounts of nuclei are present to allow for complete crystallization of the ester upon cooling.

Due to heterogeneous crystallization, the lubrication greases crystallize approximately $37 \mathrm{~K}$ above the pour point. Thus, the pour point is not suitable to judge the low temperature application behavior of greases based on trimellitate (EO) with linear alkyl chains (C8-C10).

\section{Conclusions}

This study investigates the influence of thickener type and concentration on the crystallization, melting and glass transition of greases made from three different base oil types (Groups I-III) using rheological and thermoanalytical measurements. Group I is represented by a mineral oil (MO), Group II includes amorphously solidifying synthetic lubricating oils (PAG, KR-008, PAO8), and Group III comprises the crystallizing synthetic lubricating ester oil (EO).

\subsection{Lubricating Greases Based on Mineral Oil (Group I)}

During cooling below the crystallization temperature $T_{\mathrm{c}, \text { rheo }}$, mineral oils precipitate paraffin crystals. Upon further cooling the complex viscosity reaches an absolute value of about $10^{5}$ Pas, regardless of the thickener type and concentration. The suspension formed by the deposition of paraffin crystals is responsible for the increasingly stiff consistency of the lubricating greases. On reheating, above the melting temperature $T_{\mathrm{m} \text {,rheo }}$, the absolute value of the complex viscosity returns to the initial level. The different thickener types (Li- or Ca-12-hydroxystearate) have a significant effect on crystallization $(+4 \mathrm{~K})$ and melting temperature $(-4 \mathrm{~K})$. The pour point $\left(-12^{\circ} \mathrm{C}\right)$ of the mineral oil is $3 \mathrm{~K}$ lower than the crystallization temperature of the lubricating grease and $7 \mathrm{~K}$ lower than the melting temperature. This indicates that the pour point does not properly define the lowest application temperature for mineral oil (MO) based greases.

\subsection{Lubricating Greases Based on Non-Crystallizing Synthetic Oils (Group II)}

Group II oils do not crystallize but solidify glass-like at temperatures below $-70{ }^{\circ} \mathrm{C}$. This group includes polyalphaolefin (PAO8), alkylated naphthalene (KR-008), and polypropylene glycol (PAG). The addition of Li-12-hydroxystearate does not change the glass transition temperature significantly. The absolute value of the complex viscosity of these greases increases steadily with decreasing temperature. At about $20 \mathrm{~K}$ above $T_{\mathrm{G}}$, however, the absolute value of the complex viscosity increases sharply, i.e., the slope of the $\left|\eta^{*}\right|$ vs. $T$ curve changes significantly. The onset of this steep viscosity increase is equal to the pour point of the corresponding oil and the latter thus is an appropriate measure for the lowest application temperature of these greases.

\subsection{Lubricating Greases Based on Crystallizing Synthetic Oils (Group III)}

Group (III) oils crystallize with strong supercooling effects up to cold crystallization. Trimellitate (EO) with linear C8-C10 alkyl chains belongs to this group. This ester oil (EO) shows that adding minor thickener concentrations (about $0.5 \mathrm{wt}$ \% Ca-12-hydroxystearate, $1 \mathrm{wt}$ \% Li-12-hydroxystearate) causes the ester to crystallize partly upon cooling and partly upon heating. The fraction of crystallization during cooling rises with increasing thickener concentration until the ester oil crystallizes only upon cooling. This is due to heterogeneous 
nucleation, which becomes more significant with increasing thickener concentration. As a result of heterogeneous nucleation, the crystallization temperature rises from $-45^{\circ} \mathrm{C}$ to $-20{ }^{\circ} \mathrm{C}$. In contrast, the melting temperature $T_{\mathrm{m}}$ remains constant at $7{ }^{\circ} \mathrm{C}$ independent of the thickener concentration and thickener type. The investigations show that using lubricating greases based on this ester oil below the melting temperature is not advisable. Especially for lubricating greases based on trimellitate (EO), the pour point of $-57^{\circ} \mathrm{C}$ is inappropriate as indicator for the lowest application temperature.

Author Contributions: Conceptualization, A.C. and K.-H.J.; methodology, A.C., A.H., B.H., K.-H.J. and N.W.; validation, A.C., A.H. and B.H.; formal analysis, A.C. and A.H.; investigation, A.C. and A.H.; resources, K.-H.J. and N.W.; data curation, A.C.; writing-original draft preparation, A.C.; writing-review and editing, A.C., A.H., B.H., K.-H.J. and N.W.; visualization, A.C.; supervision, K.-H.J. and N.W.; project administration, B.H., K.-H.J. and N.W.; funding acquisition, K.-H.J. and N.W. All authors have read and agreed to the published version of the manuscript.

Funding: This research was funded by Arbeitsgemeinschaft industrieller Forschungsvereinigungen "Otto von Guericke“ e.V. (AiF), Grant Number 20001N and Forschungsvereinigung Antriebstechnik e.V. (FVA), Grant Number 829I.

Acknowledgments: The authors give thanks to the members of the FVA, especially to Fuchs Schmierstoffe $\mathrm{GmbH}$, Castrol Germany $\mathrm{GmbH}$, and King Industries, for providing additional information and the base oils. In addition, we wish to thank the students Johanna Scheller, Daniel Weiß, and Maximilian Enhuber for their contribution to the manuscript as part of their bachelor thesis.

Conflicts of Interest: The authors declare no conflict of interest.

\section{Appendix A}

Table A1. Base oil, thickener type, mass concentrations of thickener, fulling penetration $\mathrm{P}_{\mathrm{W}}$ [17], and corresponding NLGI class [18] for the lubricating greases.

\begin{tabular}{|c|c|c|c|c|}
\hline Base Oil & Thickener & $w_{\text {thickener }} / \mathrm{wt} \%$ & $P_{W} / 0.1 \mathrm{~mm}$ & NLGI Class \\
\hline \multirow{5}{*}{$\mathrm{MO}$} & \multirow{5}{*}{ Li-12-hydroxystearate } & 2.0 & n.a & n.a \\
\hline & & 5.0 & $430 \pm 6$ & $000 / 00$ \\
\hline & & 10.0 & $362 \pm 9$ & 0 \\
\hline & & 15.0 & $264 \pm 2$ & $2 / 3$ \\
\hline & & 20.0 & $212 \pm 2$ & $3 / 4$ \\
\hline \multirow{12}{*}{$\mathrm{MO}$} & \multirow{12}{*}{ Ca-12-hydroxystearate } & 0.5 & n.a. & n.a. \\
\hline & & 1.0 & n.a. & n.a. \\
\hline & & 2.0 & n.a. & n.a. \\
\hline & & 3.0 & n.a. & n.a. \\
\hline & & 5.0 & n.a. & n.a. \\
\hline & & 7.8 & $454 \pm 6$ & 000 \\
\hline & & 10.0 & $427 \pm 6$ & 00 \\
\hline & & 11.0 & $335 \pm 3$ & 1 \\
\hline & & 12.1 & $244 \pm 3$ & 3 \\
\hline & & 13.0 & $221 \pm 2$ & 3 \\
\hline & & 14.0 & $204 \pm 5$ & 4 \\
\hline & & 15.8 & $195 \pm 2$ & 4 \\
\hline PAO8 & \multirow{5}{*}{ Li-12-hydroxystearate } & 22.0 & $286 \pm 4$ & 2 \\
\hline KR-008 & & 10.0 & $281 \pm 7$ & 2 \\
\hline KR-008 & & 11.0 & $247 \pm 1$ & 3 \\
\hline PAG & & 11.0 & $306 \pm 5$ & $1 / 2$ \\
\hline PAG & & 15.0 & $271 \pm 12$ & 2 \\
\hline PAO8 & \multirow{3}{*}{ Ca-12-hydroxystearate } & 22.0 & $227 \pm 9$ & 3 \\
\hline KR-008 & & 11.0 & $244 \pm 1$ & 3 \\
\hline PAG & & 11.0 & $231 \pm 5$ & 3 \\
\hline
\end{tabular}


Table A1. Cont.

\begin{tabular}{|c|c|c|c|c|}
\hline Base Oil & Thickener & $w_{\text {thickener }} / \mathbf{w t} \%$ & $P_{W} / 0.1 \mathrm{~mm}$ & NLGI Class \\
\hline \multirow{11}{*}{$\mathrm{EO}$} & \multirow{11}{*}{ Li-12-hydroxystearate } & 0.5 & n.a. & n.a. \\
\hline & & 1.0 & n.a. & n.a. \\
\hline & & 2.0 & n.a. & n.a. \\
\hline & & 3.0 & n.a. & n.a. \\
\hline & & 5.0 & n.a. & n.a. \\
\hline & & 8.0 & n.a. & n.a. \\
\hline & & 11.0 & $442 \pm 6$ & $000 / 00$ \\
\hline & & 13.0 & $361 \pm 5$ & 0 \\
\hline & & 15.8 & $272 \pm 5$ & 2 \\
\hline & & 18.0 & $252 \pm 1$ & $2 / 3$ \\
\hline & & 20.0 & $183 \pm 10$ & 4 \\
\hline \multirow{12}{*}{$\mathrm{EO}$} & \multirow{12}{*}{ Ca-12-hydroxystearate } & 0.5 & n.a. & n.a. \\
\hline & & 1.0 & n.a. & n.a. \\
\hline & & 2.0 & n.a. & n.a. \\
\hline & & 3.0 & n.a. & n.a. \\
\hline & & 5.0 & n.a. & n.a. \\
\hline & & 7.0 & $438 \pm 12$ & $000 / 00$ \\
\hline & & 8.0 & $437 \pm 8$ & $000 / 00$ \\
\hline & & 9.0 & $434 \pm 8$ & $000 / 00$ \\
\hline & & 10.0 & $316 \pm 3$ & 1 \\
\hline & & 11.0 & $254 \pm 2$ & $2 / 3$ \\
\hline & & 12.0 & $242 \pm 4$ & 3 \\
\hline & & 13.0 & $253 \pm 5$ & $2 / 3$ \\
\hline
\end{tabular}

n.a.: not applicable

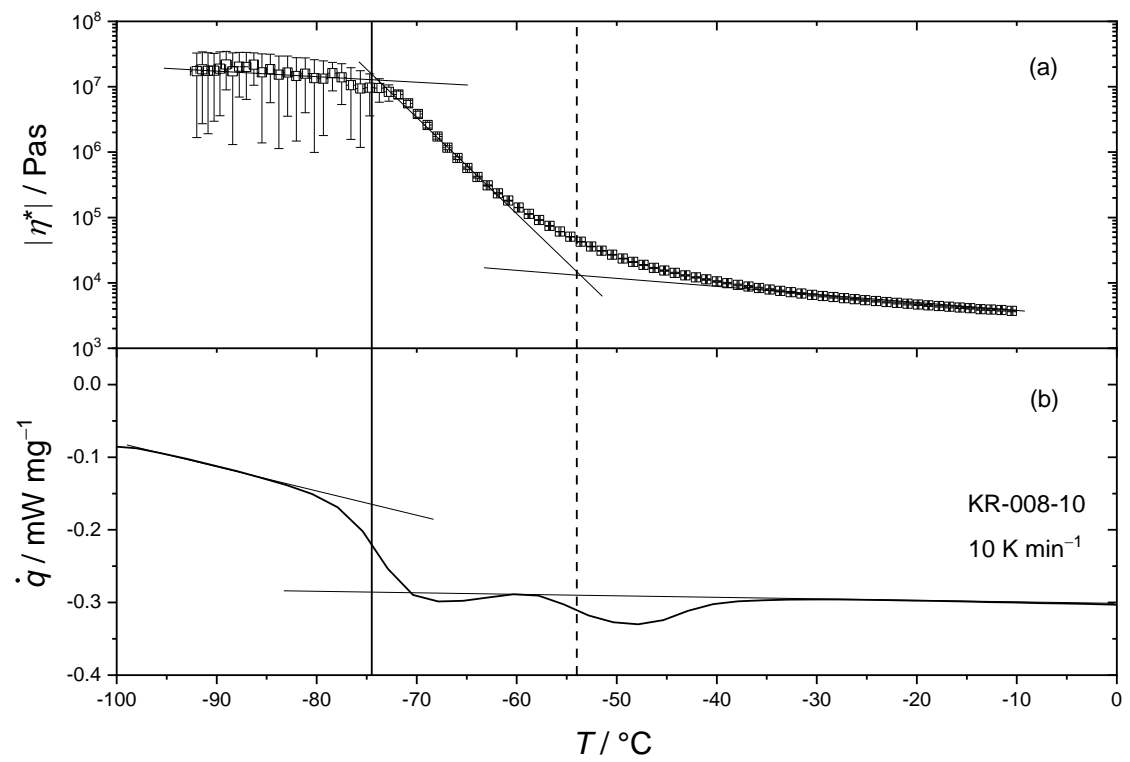

Figure A1. (a) Complex viscosity $\left|\eta^{*}\right|$ as a function of the temperature of the lubricating grease made from the base oil KR-008 with $10 \mathrm{wt} . \%$ Li-12-hydroxystearate as a thickener (KR-008-10), measured in oscillatory shear with the deformation $\gamma=0.05 \%$, angular frequency $\omega=10 \mathrm{rad} \mathrm{s}^{-1}$ and cooling rate of $-10 \mathrm{~K} \mathrm{~min}^{-1}$. Lines are to guide the eye. (b) Specific heat flow $\dot{q}$ of the KR-008-10 grease at a heating rate of $10 \mathrm{~K} \mathrm{~min}^{-1}$. The grease shows a glass transition temperature $T_{\mathrm{G}}$ at $-74.5 \pm 0.4^{\circ} \mathrm{C}$, marked by a solid line. The dashed line marks the pour point for the base oil KR-008 of $-54{ }^{\circ} \mathrm{C}$. 


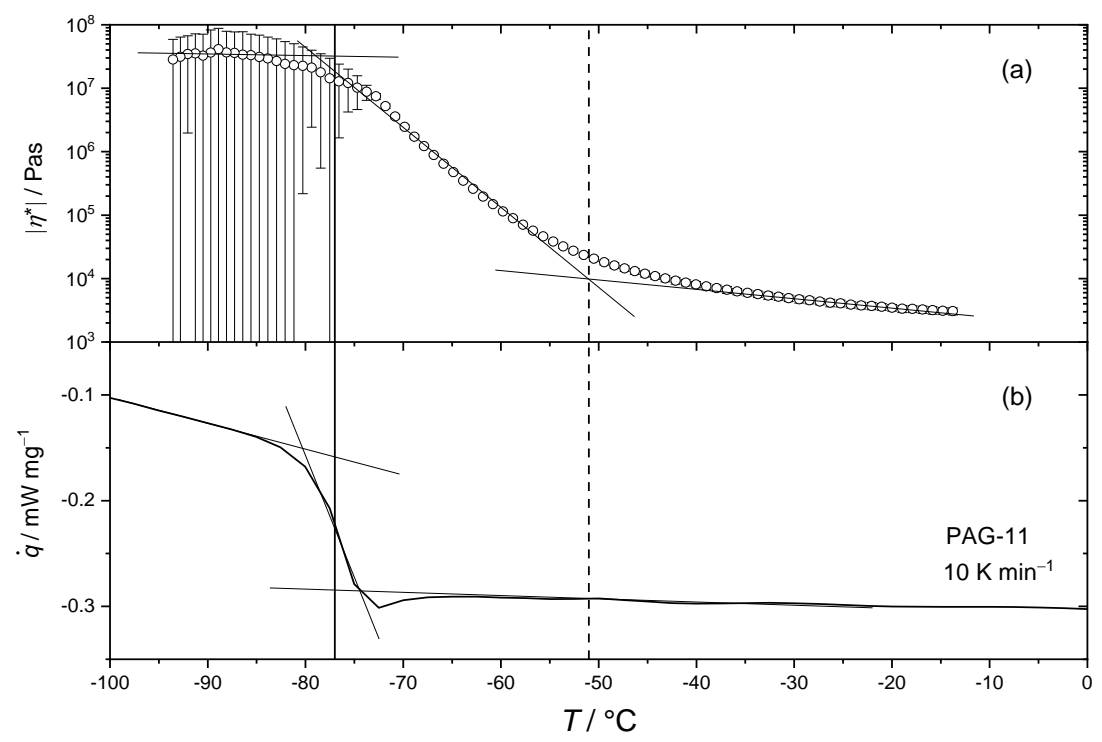

Figure A2. (a) Complex viscosity $\left|\eta^{*}\right|$ as a function of temperature of the lubricating grease made from the base oil PAG with $11 \mathrm{wt} . \%$ Li-12-hydroxystearate as a thickener (PAG-11), measured in oscillatory shear with the deformation $\gamma=0.05 \%$, angular frequency $\omega=10 \mathrm{rad} \mathrm{s}^{-1}$ and cooling rate of $-10 \mathrm{~K} \mathrm{~min}^{-1}$. Lines are to guide the eye. (b) Specific heat flow $\dot{q}$ of the PAG-10 grease at a heating rate of $10 \mathrm{~K} \mathrm{~min}^{-1}$. The grease shows a glass transition temperature $T_{\mathrm{G}}$ at $-77 \pm 0.2{ }^{\circ} \mathrm{C}$, marked by a solid line. The dashed line marks the pour point for the base oil PAG of $-51^{\circ} \mathrm{C}$.

\section{References}

1. De Laurentis, N.; Cann, P.; Lugt, P.M.; Kadiric, A. The Influence of Base Oil Properties on the Friction Behaviour of Lithium Greases in Rolling/Sliding Concentrated Contacts. Tribol. Lett. 2017, 65, 128. [CrossRef]

2. Lan, Z.; Liu, S.; Xiao, H.; Wang, D. Frictional Behavior of Wax-Oil Gels Against Steel. Tribol. Lett. 2017, 65, 88. [CrossRef]

3. Conrad, A.; Hodapp, A.; Hochstein, B.; Willenbacher, N.; Jacob, K.-H. Low-Temperature Rheology and Thermoanalytical Investigation of Lubricating Oils: Comparison of Phase Transition, Viscosity, and Pour Point. Lubricants 2021, 9, 99. [CrossRef]

4. D02 Committee. ASTM D4693: Test Method for Low-Temperature Torque of Grease-Lubricated Wheel Bearings; ASTM International: West Conshohocken, PA, USA, 2017.

5. D02 Committee. ASTM D1478: Test Method for Low-Temperature Torque of Ball Bearing Grease; ASTM International: West Conshohocken, PA, USA, 2020.

6. D02 Committee. ASTM D97 Test Method for Pour Point of Petroleum Products; ASTM International: West Conshohocken, PA, USA, 2017.

7. Webber, R.M. Low-Temperature rheology of lubricating mineral oils: Effects of cooling rate and wax crystallization on flow properties of base oils. J. Rheol. 1999, 43, 911-923. [CrossRef]

8. Li, S.; Bouzidi, L.; Narine, S.S. Lubricating and Waxy Esters, V: Synthesis, Crystallization, and Melt and Flow Behaviors of Branched Monoesters Incorporating 9-Decenol and 9-Decenoic Acid. Ind. Eng. Chem. Res. 2014, 53, 12339-12354. [CrossRef]

9. Turnbull, D. Kinetics of Heterogeneous Nucleation. J. Chem. Phys. 1950, 18, 198-203. [CrossRef]

10. Glicksman, M.E. Principles of Solidification: An Introduction to Modern Casting and Crystal Growth Concepts; Springer Science \& Business Media LLC: New York, NY, USA, 2011; ISBN 9781441973436.

11. March, N.H.; Street, R.A.; Tosi, M.P. Amorphous Solids and the Liquid State; Springer: Boston, MA, USA, 1985.

12. Delgado, M.A.; Sánchez, M.C.; Valencia, C.; Franco, J.M.; Gallegos, C. Relationship Among Microstructure, Rheology and Processing of a Lithium Lubricating Grease. Chem. Eng. Res. Des. 2005, 83, 1085-1092. [CrossRef]

13. Delgado, M.A.; Valencia, C.; Sánchez, M.C.; Franco, J.M.; Gallegos, C. Influence of Soap Concentration and Oil Viscosity on the Rheology and Microstructure of Lubricating Greases. Ind. Eng. Chem. Res. 2006, 45, 1902-1910. [CrossRef]

14. Delgado, M.A.; Secouard, S.; Valencia, C.; Franco, J.M. On the Steady-State Flow and Yielding Behaviour of Lubricating Greases. Fluids 2019, 4, 6. [CrossRef]

15. Yeong, S.K.; Luckham, P.F.; Tadros, T.F. Steady flow and viscoelastic properties of lubricating grease containing various thickener concentrations. J. Colloid Interface Sci. 2004, 274, 285-293. [CrossRef] [PubMed]

16. D02 Committee. ASTMD7346.9011: Standard Test Method for No Flow Point and Pour Point of Petroleum Products and Liquid Fuels; ASTM International: West Conshohocken, PA, USA, 2015.

17. DIN Deutsches Institut für Normung e.V. DIN ISO 2137: Petroleum Products and Lubricants_Determination of Cone Penetration of Lubricating Greases and Petrolatum; Beuth Verlag GmbH: Berlin, Germany, 2007. 
18. DIN Deutsches Institut für Normung e.V. DIN 51818 Lubricants; Consistency Classification of Lubricating Greases; Beuth Verlag GmbH: Berlin, Germany, 1981.

19. Mortimer, R.G. Physical Chemistry, 2nd ed.; Harcourt/Academic Press: San Diego, CA, USA, 2000; ISBN 9780080538938.

20. DIN Deutsches Institut für Normung e.V. Differential Scanning Calorimetry (DSC)—Part 7: Determination of Crystallization Kinetics (ISO 11357-7:2015); Beuth Verlag GmbH: Berlin, Germany, 2015. 